\title{
Is the Ramgarh thrust equivalent to the Main Central thrust in central Nepal?
}

\author{
Kyle P Larson* and Laurent Godin \\ Geological Sciences \& Geological Engineering, Queen's University, Kingston, CANADA \\ * For correspondence, email: larson@students.geol.queensu.ca
}

Recent studies of the Main Central thrust (MCT), as exposed in the Nepalese Himalaya, have attempted to elucidate its character, contentious definition and locality (e.g. Searle et al. 2008, Imayama and Arita 2008). Examination of vertical exposures in the Budhi Gandaki and Darondi rivers, which drain the ManasluHimal Chuli massif, supported by detailed thermobarometry and microstructural analyses provide the means to critically evaluate the applicability of such studies.

The Ramgarh thrust is defined in western Nepal as the fault that juxtaposes green-schist facies rocks on top of lowergrade Lesser Himalayan series rocks. The Ramgarh thrust has not been mapped previously in the Budhi Gandaki or Darondi valleys; however, it has been inferred in the adjacent Annapurna and Langtang Himalaya. The geology of the Budhi Gandaki and Darondi valleys is dominated by a $>30 \mathrm{~km}$ thick package of transposed medium-to high grade metamorphic rock of the Greater Himalayan series. The upper boundary of the highly strained section is the base of the top-to-the-north sense shears zone of the South Tibetan detachment system, while the lower boundary of the highly strained package is interpreted to be the MCT using the definition of Searle et al. (2008). In the Budhi Gandaki, rocks in the hanging wall of the MCT show evidence of Tertiary metamorphism, display abundant $\mathrm{C} / \mathrm{S} / \mathrm{C}$ ' fabrics, yield quartz c-axis crystallographic preferred orientations that suggest horizontal stretching, and contain partial melt at higher structural levels. Rocks below the MCT often preserve primary sedimentary features such as bedding, contain abundant detrital porphyroclasts, and are characterized by large-scale folding indicative of vertical thickening. Mapping the MCT at the base of the transposed, pervasively deformed rock package exposed in the Budhi Gandaki and Darondi valleys positions the fault more than $20 \mathrm{~km}$ farther south than previous studies.

In the Budhi Gandaki and Darondi valleys, the MCT separates greenschist or higher-grade metamorphic rocks over unmetamorphosed-to low-grade rocks of the Lesser Himalayan series, similar to the Ramgarh thrust in western Nepal. There is nowhere in the Budhi Gandaki or Darondi valleys direct evidence for the largescale structural repetition of lithologic units or a localization of strain along a discrete fault above the MCT; analysis of quartz petrofabrics further indicates that the entire meta-sedimentary package was likely deformed at temperatures exceeding $500^{\circ} \mathrm{C}$. Furthermore, thermobarometric and $40 \mathrm{Ar} / 39 \mathrm{Ar}$ cooling profiles across the study area do not contain any disturbances that would necessitate mapping a thrust fault above the MCT. We therefore suggest that the Ramgarh thrust mapped in other areas may actually be equal to the MCT in the Budhi Gandaki and Darondi valleys.

\section{References}

Searle MP, RD Law, L Godin, KP Larson, MP Streule, JM Cottle and MJ Jessup. 2008. Defining the Main Central thrust in Nepal. Journal of the Geological Society 165: 523-534

Imayama $\mathrm{T}$ and $\mathrm{K}$ Arita. 2008. Nd isotopic data reveal the material and tectonic nature of the Main Central Thrust zone in Nepal Himalaya. Tectonophysics doi:10.1016/j.tecto.2007.11.051 